\title{
ENFERMEDADES Y COMPONENTES DE RENDIMIENTO EN DIECISÉIS GENOTIPOS DE FRÉJOL EN QUEVEDO, ECUADOR
}

\section{DISEASES AND YIELD COMPONENTS OF SIXTEEN BEAN GENOTYPES IN QUEVEDO, ECUADOR}

\author{
Felipe Garcés-Fiallos ${ }^{1,2}$; Ángel Aguirre-Calderón ${ }^{3}$; Rafael Garcés-Estrella ${ }^{4}$, Eduardo Díaz-Ocampo $^{5}$, \\ Fernando Sánchez-Mora²; Oscar Prieto-Benavides ${ }^{2}$ \\ ${ }^{1}$ Becario de la Secretaría Nacional de Educación Superior, Ciencia, Tecnología e Innovación del Ecuador \\ ${ }^{2}$ Dirección de Investigación Cientifica y Tecnológica, Universidad Técnica Estatal de Quevedo. \\ Campus Finca Experimental "La María". \\ ${ }^{3}$ Escuela de Ingeniería Agropecuaria. Facultad de Ciencias Pecuarias, Universidad Técnica Estatal de Quevedo. \\ Campus Finca Experimental "La María”, km 7 vía Quevedo-El Empalme. C. P. 73. Mocache, Los Ríos, Ecuador. \\ ${ }^{4}$ Escuela de Ingeniería Forestal. Facultad de Ciencias Ambientales, Universidad Técnica Estatal de Quevedo. \\ Campus Ing. Manuel Haz Álvarez. \\ ${ }^{5}$ Dirección de posgrado, Universidad Técnica Estatal de Quevedo. Campus Ing. Manuel Haz Álvarez, $\mathrm{km} 1.5 \mathrm{vía}$ a Santo \\ Domingo de los Tsáchilas. C. P. 73. Quevedo, Los Ríos, Ecuador.
}

Emails: felipegarces23@yahoo.com; angeljaguirrec@hotmail.es; rgarces@uteq.edu.ec; ediaz@uteq.edu.ec; fernandosanchezm23@hotmail.com; oscarprietob@hotmail.com

\section{ReSumen}

$\mathrm{E}^{\mathrm{I}}$ l objetivo del trabajo fue cuantificar la severidad de enfermedades, el rendimiento y sus componentes, y su relación en 16 genotipos de fréjol durante la época lluviosa del 2011, en Quevedo, Ecuador. El diseño experimental empleado fue en Bloques Completos al Azar (DBCA) con 16 tratamientos y cuatro repeticiones. Se estimó la severidad (\%) de la mustia hilachosa, la roya y virosis de manera conjunta, durante los estadíos R5 (prefloración), R6 (floración) y R7 (formación de vainas). Después de la cosecha se cuantificó los componentes de rendimiento por planta (número de vainas, número de granos, número de granos por vaina, peso de granos y vainas estériles) y rendimiento de granos $\left(\mathrm{kg} \mathrm{ha}^{-1}\right)$ corregidos al 13\% de humedad. Las líneas Cf4 0-0-2-1 y EVG-16-08 con 28.3\% presentaron la menor severidad final (estadío fenológico R7) de enfermedades. Se determinaron como componentes secundarios importantes al número de vainas por planta, número de granos por planta y peso de granos por planta, por haber obtenido regresiones significativas $(\mathrm{p}<0.01)$ con el rendimiento. En función del análisis de conglomerados, se destacaron la variedad extranjera FTS Soberano y la línea promisoria EVG-16-08 con cualidades productivas superiores.

Palabras clave: Phaseolus vulgaris L., Rhizoctonia solani Kuhn, Uromyces appendiculatus Pers.:Pers., Bean common mosaic virus, rendimiento y sus componentes

Recibido: 10-diciembre-2012. Recibido en forma corregida: 15-febrero-2013. Aceptado: 30-mayo-2013.

Publicado como ARTíCULO CIENTÍFICO en Ciencia y Tecnología 6(2): 31-39

Julio-Diciembre de 2013

ISSN 1390-4051 impreso; ISSN 1390-4043 electrónico

(C) Ciencia y Tecnología. UTEQ. Quevedo-Ecuador

\section{AbstraCt}

$\mathrm{T}$ he aim of this study was to quantify the severity of foliar diseases, yield and its components, in 16 bean genotypes during the rainy season of 2011, in Quevedo, Ecuador. The experimental design used was the randomized complete block (RCBD) with 16 treatments and four replications. Mutual effect of the web blight severity (\%), rust and viruses, during stages R5 (preflowering), R6 (flowering) and R7 (pod formation) was estimated. After harvesting, yield components per plant were quantified (pods number, seeds number, number of seeds per pod, grains weight and sterile pods) as well as grain yield $\left(\mathrm{kg} \mathrm{ha}^{-1}\right)$ corrected to $13 \%$ of the moisture content. The lines Cf4 0-0-2-1 and EVG-1608 showed the lowest final severity (phenological stage R7) of foliar diseases (28.3\%). Number of pods, grains number and grains weight per plant were determined as important secondary components, showing significant yield regressions $(\mathrm{p}<0.01)$. Cluster analysis clearly distinguished foreign variety FTS Soberano and the lineEVG 16-08, as promising lines with higher production qualities.

Key words: Phaseolus vulgaris L., Rhizoctonia solani Kuhn, Uromyces appendiculatus Pers.:Pers., Bean common mosaic virus, grain yield and its components. 


\section{INTRODUCCIÓN}

$\mathrm{L}$ a importancia del fréjol (Phaseolus vulgaris L.) en el Ecuador, radica en que es uno de los alimentos predilectos de la población, por su valor accesible, el contenido de grasas y proteínas, incluso su valor nutritivo es comparado con la carne roja (Garcés-Fiallos, 2013). El grano de este cultivo es consumido casi por la totalidad de la población, siendo también fuente de ingreso para pequeños y medianos productores (Garcés-Fiallos, 2011a); es la leguminosa con mayor área de cultivo y consumo, en grano seco y con alto contenido de humedad, cosechada antes de la madurez fisiológica (grano fresco) (Ernest et al., 2008).

El promedio de la superficie total cosechada de esta leguminosa en los cinco últimos años fue de 22,186 ha, correspondientes a 3,410 ha para fréjol arbustivo (hábito de crecimiento determinado) $\mathrm{y}$ 18,776 ha para volubles (hábito de crecimiento indeterminado). El rendimiento promedio para fréjol seco es de $350 \mathrm{~kg} \mathrm{ha}^{-1} \mathrm{y}$ para legumbre verde de 1,340 $\mathrm{kg} \mathrm{ha}^{-1}$ (INEC, 2002).

En el país se siembran variedades de fréjol arbustivo en la sierra en las provincias de Carchi e Imbabura (Valle del Chota), Pichincha (Guayllabamba y Tumbaco), Tungurahua (Patate), Azuay (Gualaceo y Yunguilla) y Loja (Catamayo, Malacatos y Vilcabamba), así como materiales volubles en las provincias de Carchi, Imbabura, Pichincha, Chimborazo, Bolívar y Loja (INIAP, 1999). En la costa, en las provincias del Guayas (Milagro, Naranjito y Pedro Carbo) y Los Ríos (Babahoyo, Vinces y Quevedo) se producen los dos tipos (GodoyMontiel et al., 2011). Esta leguminosa es cultivada en diferentes condiciones agroclimáticas, desde 0 hasta más de 2.000 metros sobre el nivel del mar.

El fréjol que se cultiva en la costa ecuatoriana procede en su mayoría de introducciones (Voysest, 2000), siendo apreciados los granos de colores rojos en Los Ríos; blancos, bayos, rojos y canarios (amarillos) en Guayas; y amarillos en El Oro.

El rendimiento de fréjol en el Ecuador es uno de los más bajos a nivel sudamericano, debiéndose principalmente al ataque de enfermedades. Las enfermedades más comunes en este cultivo en la zona central del Litoral Ecuatoriano son la roya (Uromyces apendiculatus Pers.:Pers.), mustia hilachosa [Rhizoctonia solani (Kuhn)] y virosis, así como las pudriciones radiculares [Fusarium spp., $R$. solani y Macrophomina phaseolina (Tassi) Goid.] (Garcés-Fiallos, 2010; 2011b; 2013; Garcés-Fiallos y Gamarra, 2012a; Garcés-Fiallos et al., 2012). De estas, la mustia hilachosa es la enfermedad que posee mayor incidencia, conociéndose inclusive que puede afectar el rendimiento (Garcés-Fiallos, 2011b) y algunos de sus componentes como número de nudos por planta, número de vainas por planta y número de semillas por planta (Garcés-Fiallos y Gamarra, 2012b).

La productividad de granos es una carácter complejo, resultante de la expresión y de la asociación de diferentes componentes, considerados importantes en el proceso de selección de nuevos genotipos (Amorim et al., 2008). El rendimiento así como sus componentes son independientes uno del otro, contribuyendo directamente al potencial de producción de la planta, no siendo el rendimiento por sí solo como el mejor criterio de selección en programas de mejoramiento de fréjol, debido a su baja heredabilidad y alta interacción con el medio ambiente (Kuruvadi y Cortinas-Escobar, 1987). Así mismo, el conocimiento de la interrelación entre caracteres (componentes de rendimiento) es de gran interés en el mejoramiento de plantas (Barili et al., 2010).

Estas informaciones sobre la interrelación de la producción de grano y de sus componentes primarios, para el cambio climático y la diversidad de ambientes en un país en los cuales se explora el cultivo de fréjol, son deficientes (Coelho et al., 2002), por lo que estos análisis ayudarían en la elección correcta de genotipos de fréjol y proporcionaría información relevante sobre la relación de dichos componentes de producción.

En la provincia de Los Ríos y su zona de influencia (cantones aledaños de las provincias de Guayas, Manabí, Bolívar y Azuay), se utiliza mayormente materiales recomendados para otras zonas del país (Guayas, Manabí o Imbabura), o a su vez semillas provenientes del mercado informal, que casi siempre el productor no obtiene una germinación superior al $80 \%$, repercutiendo en una baja producción del cultivo y exigua rentabilidad del productor.

El desarrollo de nuevos cultivares con mayor potencial genético para la productividad es la principal meta de los programas de mejoramiento (Barili et al., 2011). En vista de esta situación, la Dirección de Investigación Científica y Tecnológica-DICYT de la Universidad Técnica Estatal de Quevedo-UTEQ, viene trabajando en el mejoramiento del fréjol, para en un futuro lanzar un material con excelentes características sanitarias y productivas para esta zona del Ecuador, por lo que el objetivo de este trabajo fue cuantificar la severidad de enfermedades, el rendimiento y sus componentes, y su relación en 16 genotipos de fréjol durante la época lluviosa del 2011, en Quevedo, Ecuador. 


\section{Materiales Y MÉTOdos}

L a presente investigación se efectuó durante la época Iluviosa (22 febrero - 02 junio) del 2011 en la Finca Experimental La María propiedad de la UTEQ, ubicada en el kilómetro $7 \frac{1}{2}$ vía a El Empalme perteneciente al cantón Mocache, provincia de Los Ríos, cuyas coordenadas geográficas son: $79^{\circ} 27^{\prime}$ longitud Oeste y $01^{\circ} 06^{\prime}$ de latitud Sur con una altura de $73 \mathrm{msnm}$.

Los genotipos de fréjol evaluados fueron tres líneas promisorias F6 Cf6 0-0-4-8, Cf6 0-0-4-9 y Cf6 0-0-5-7 (hábito de crecimiento determinado tipo Ia), obtenidas del cruzamiento Cf6 (variedad INIAP-473-Boliche y la línea promisoria EVG-6-248); tres líneas promisorias F5 Cf4 0-0-2-1, Cf4 0-0-3-11 y Cf4 0-0-4-8 (todas con hábito de crecimiento determinado tipo Ia), obtenidas del cruzamiento Cf4 (línea Cf1 0-14-1-2 y línea promisoria EVG-6-248); tres líneas promisorias avanzadas SER 03, SER 08 y SER 31 (hábito de crecimiento indeterminado tipo IIb); dos líneas avanzadas EVG-16-08 y EVG-06103 (hábito de crecimiento indeterminado y determinado tipo Ia, respectivamente). Se utilizaron como testigos la variedad criolla Cuarentón, la variedad comercial nacional INIAP-473-Boliche (Guamán et al., 2003), la variedad comercial colombiana CAL-96 (todas de hábito de crecimiento determinado tipo Ia) y dos variedades comerciales brasileñas FTS Soberano y BRS Valente (hábito de crecimiento indeterminado, grupo negro).

Cada parcela constó de cinco hileras de $10 \mathrm{~m}^{2}$, considerando como parcela útil $5 \mathrm{~m}^{2} \mathrm{y}$ un área total del experimento de $736 \mathrm{~m}^{2}$. El diseño experimental empleado fue un Bloques Completos al Azar (DBCA) con 16 tratamientos y cuatro repeticiones. Se realizaron dos pases de rastra a una profundidad de $20 \mathrm{~cm}$, tres días antes de la siembra, la misma que fue realizada el 22 de febrero del 2011. La semilla fue tratada con el fungicida carbendazim (i. a.) en dosis de $200 \mathrm{~mL}$ por cada $100 \mathrm{~kg}$ de semillas, y luego sembrada a una distancia de 0.20 $\mathrm{cm}$ entre plantas y $0.50 \mathrm{~cm}$ entre hileras. Se realizaron dos fertilizaciones, la primera a los 16 días después de la siembra (DDS) utilizando fuentes de N, F y P, en una relación de 30-60-30, en dosis de 150 kilogramos ha $^{-1}$, y la segunda a los 30 días DDS utilizando una fuente de $\mathrm{N}$ al $46 \%$ en dosis de 100 kilogramos ha-1 distribuido en la línea de siembra a una distancia de $5 \mathrm{~cm}$ de la planta. El control de insectos plagas se realizó utilizando los insecticidas lambdacihalotrina, clorpirifos e imidacloprid con dosis de $0.2,2.0$ y $0.5 \mathrm{~L} \mathrm{ha}^{-1}$, respectivamente. No fue aplicado fungicida en la parte aérea. La cosecha se la realizó desde el 16 de mayo hasta el 02 de junio (100 días) de forma manual, en las hileras de cada parcela útil cuando las vainas estuvieron totalmente secas durante el estadío fenológico reproductivo R9 (Hall, 1994).

Durante los estadíos fenológicos reproductivos R5 (prefloración), R6 (floración plena) y R7 (formación de vainas), descritos por Hall (1994), fue estimada la severidad (\%) de la mustia hilachosa [R. solani (Kuhn)], la roya (U. appendiculatus Pers.:Pers.) y virosis [Bean common mosaic virus (BCMV)], de manera conjunta. Para esto, se marcaron seis plantas (dos en cada hilera de la parcela útil) con cuerdas de polietileno color amarillo. En cada planta se estimó el porcentaje de daño ocasionado por las tres enfermedades presentes en esta época, mediante la evaluación visual de cada uno de los trifolios, considerándose damnificada la planta que presentaba necrosis o muerte del tejido foliar, similar a la metodología usada por Garcés-Fiallos (2013). Para la descripción de las enfermedades viróticas se utilizaron las referencias de Bianchini et al. (2005), Hall (1994) y Garcés-Fiallos (2010).

Después de la cosecha fueron cuantificados los componentes de rendimiento por planta (número de vainas, número de granos, número de granos por vaina, peso de granos y vainas estériles), en 10 plantas recolectadas al azar en la parcela útil. Para el rendimiento de granos $\left(\mathrm{kg} \mathrm{ha}^{-1}\right)$, se utilizaron todas las plantas de la parcela útil (incluyendo las 10 plantas donde fueron analizados los componentes de rendimiento). Para el peso de los granos se utilizó una balanza electrónica (marca KERN NDE modelo 6K2IP), siendo posteriormente estos valores transformados considerando el $13 \%$ de humedad.

Los datos meteorológicos fueron obtenidos en la División de Meteorología, Departamento de Sinóptica del Instituto Nacional Autónomo de Investigaciones Agropecuarias (INIAP), Quevedo.

Para la comparación entre las medias de los tratamientos se empleó la prueba de Tukey al 5\% de probabilidad de error. Para este análisis estadístico fue utilizado el software SAS 9.0 (SAS, 2002). Se relacionó la severidad (\%) de enfermedades foliares durante los estadíos fenológicos R5, R6 y R7, el rendimiento de granos y los componentes de rendimiento del fréjol, realizando para esto el análisis de regresión simple con su probabilidad por la prueba de $\mathrm{F}$, utilizándose el programa ASSISTAT Versión 7.5 beta (Silva y Azevedo, 2002).

Fueron realizados los testes de Barlett y de ShapiroWilks, para verificar la existencia de homocedasticidad de variancias y normalidad de los residuos. Para la relación entre los distintos genotipos se obtuvo el promedio de la mayoría de las variables productivas evaluadas (excepto el número de vainas estériles), midiéndola por medio del coeficiente de similaridad, mediante el análisis de conglomerados, utilizando el método de Ward, obteniendo su respectivo dendograma. Para este análisis se utilizó el programa INFOSTAT (2011). 


\section{Resultados Y disCuSión}

$\mathrm{L}$ as condiciones climáticas durante los 100 días que el cultivo de fréjol fue establecido en el campo, se muestran en el Cuadro 1. La temperatura promedio a lo largo del cultivo fue de $25.2^{\circ} \mathrm{C}$, humedad relativa promedio de $86.4 \%$, heliofanía total de 357.6 horas luz y una precipitación pluvial total de $906.5 \mathrm{~mm}$. Estas condiciones fueron normales en comparación con años anteriores.

Para la variable severidad ocasionado por las enfermedades, solamente existieron diferencias estadísticas significativas entre cada una de las líneas y variedades, durante los estadíos fenológicos reproductivos R5 y R7 (Cuadro 2).
Estos valores se ubicaron entre 3.3 (Cf4 0-0-4-8) y 7.3\% (SER 08), entre 25.0 (Cf4 0-0-4-8) y 33.0\% (SER 31), y entre 28.3 (Cf4 0-0-2-1 y EVG-16-08) y 36.4\% (SER 31) durante los estadíos R5, R6 y R7, respectivamente. Aunque fueron encontradas y evaluadas la mustia hilachosa, roya y virosis, se destacó la primera. Ésta se presenta en terrenos infectados con períodos prolongados de lluvias, temperatura y humedad relativa promedio de $24^{\circ} \mathrm{C}$ y $80 \%$, respectivamente (Rodríguez et al., 1999; Nechet y Halfeld-Vieira, 2007), condiciones similares a las del Trópico húmedo ecuatoriano. Específicamente en la parte alta del Río Guayas, esta enfermedad tiene importancia única, pues es la que predomina sobre las demás, convirtiéndose así en un problema para quién cultiva esta leguminosa (Garcés-Fiallos, 2011a).

Cuadro 1. Condiciones climáticas obtenidas durante el desarrollo del experimento de 16 materiales de fréjol evaluados durante la época lluviosa del 2011

\begin{tabular}{lrrrrc}
\hline Condiciones climáticas & Febrero & Marzo & Abril & Mayo & Días del cultivo \\
\hline Temperatura promedio $\left({ }^{\circ} \mathrm{C}\right)$ & 25.20 & 27.00 & 25.60 & 25.50 & 25.90 \\
Humedad relativa promedio (\%) & 86.00 & 89.00 & 87.00 & 85.00 & 86.40 \\
Heliofanía total (horas luz) & 76.60 & 100.90 & 123.20 & 97.70 & 357.60 \\
Precipitación pluvial total $(\mathrm{mm})$ & 489.50 & 104.30 & 725.60 & 9.90 & 906.50 \\
\hline
\end{tabular}

${ }^{1}$ Días transcurridos desde la fecha de siembra hasta la cosecha de todos los materiales establecidos en el campo.

Los tres materiales SER 03, SER 08 y SER 31 de crecimiento indeterminado, fueron los que obtuvieron mayor severidad. La línea SER 31 alcanzó el promedio más alto en comparación con los demás genotipos (Cuadro 2). En comparación con la investigación realizada por Garcés-Fiallos (2011a), cuantificando la mustia hilachosa en siete materiales de fréjol (SER 03, SER 08, SER 31, EVG-16-08, EVG-06-103, CAL 96 e INIAP-473-Boliche) durante la época seca del año 2010, obtuvo una severidad de 25.5 (SER 31) y $38.0 \%$ (SER 03 y SER 08), siendo estos materiales superiores sanitariamente a los demás. Las diferencias encontradas en ambas investigaciones se debió posiblemente a la época de siembra, puesto que durante el año agrícola que se estableció el presente experimento (época lluviosa), se presentó una precipitación pluvial total de $906.5 \mathrm{~mm}$ (Cuadro 1), lo que podría haber originado un ambiente ideal para las enfermedades evaluadas.

Se evidenció también, un aumento de más de cinco veces en la severidad promedio de $5.5 \%$ durante R5 a 28.1\% durante R6, entre tanto, se encontró un menor aumento durante R6 a R7 (31.2\%) (Cuadro 2). Esto posiblemente se debió a que durante los estadíos R5 (prefloración) y R6 (floración plena), existe una mayor oferta de tejido foliar sano, en comparación con el estadío R7 (formación de vainas), aumentando rápidamente el proceso infeccioso por parte de los patógenos. Mientras que enfermedades durante un estado fenológico del fréjol más avanzado, puede existir una competencia entre los patógenos, siendo este último hecho corroborado por Zaiter et al. (1990) con $U$. appendiculatus y el virus BCMV, y Bassanezi et al. (1998) con U. appendiculatus, Phaeoisariopsis grisiola y el virus Bean Line Pattern Mosaic Virus (BLPMV).

Aunque no fueron cuantificadas las pudriciones radiculares, se evidenció la pudrición del tallo y raíz de esclerotinia, constatándose en este experimento la presencia de micelio y microesclerocios de Sclerotium roffsi en plantas de fréjol. Esta sería la primera ocurrencia documentada de esta enfermedad en esta zona del Ecuador, ya que ha sido relatada por Espinoza (2004) en la cuenca baja del Río Guayas.

Existió un comportamiento estadístico diferenciado entre los genotipos estudiados en todas las variables productivas evaluadas (Cuadro 3). Los materiales que estadísticamente obtuvieron superioridad para número de vainas por planta, número de granos por planta y número de granos por vaina, fueron la variedad FTS Soberano y la línea EVG-16-08. Para peso de granos por planta y rendimiento, el material destacado fue la variedad comercial FTS Soberano. Entre tanto, para el menor número de vainas estériles se destacaron estadísticamente los materiales Cf6 0-0-4-8, Cf6 0-0-4-9, SER 03, SER 08, SER 31, CAL 96, EVG-16-08, Cuarentón y FTS 
Cuadro 2. Severidad ocasionada por enfermedades en 16 materiales de fréjol evaluados durante la época lluviosa del 2011

\begin{tabular}{llcl}
\hline \multirow{2}{*}{ Material genético } & \multicolumn{3}{c}{$\begin{array}{c}\text { Severidad (\%) ocasionada por } \\
\text { enfermedades foliares }\end{array}$} \\
\cline { 2 - 4 } & \multicolumn{1}{c}{$\mathbf{R 5}^{\mathbf{1}}$} & $\mathbf{R 6}^{\mathbf{2}}$ & $\mathbf{R 7}^{\mathbf{3}}$ \\
\hline Cf6 0-0-4-8 & $4.70 \mathrm{abc}$ & 25.40 & $30.80 \mathrm{ab}$ \\
Cf6 0-0-4-9 & $3.70 \mathrm{c}$ & 28.40 & $32.10 \mathrm{ab}$ \\
Cf6 0-0-5-7 & $5.70 \mathrm{abc}$ & 27.90 & $30.40 \mathrm{ab}$ \\
Cf4 0-0-2-1 & $6.00 \mathrm{abc}$ & 25.00 & $28.30 \mathrm{~b}$ \\
Cf4 0-0-3-11 & $6.70 \mathrm{ab}$ & 26.70 & $29.70 \mathrm{ab}$ \\
Cf4 0-0-4-8 & $3.30 \mathrm{c}$ & 25.00 & $29.20 \mathrm{ab}$ \\
SER 03 & $4.00 \mathrm{bc}$ & 26.30 & $29.60 \mathrm{ab}$ \\
SER 08 & $7.30 \mathrm{a}$ & 29.60 & $32.50 \mathrm{ab}$ \\
SER 31 & $7.00 \mathrm{a}$ & 33.00 & $36.40 \mathrm{a}$ \\
CAL 96 & $6.70 \mathrm{ab}$ & 30.40 & $32.10 \mathrm{ab}$ \\
EVG-16-08 & $5.70 \mathrm{abc}$ & 25.40 & $28.30 \mathrm{~b}$ \\
EVG-06-103 & $6.00 \mathrm{abc}$ & 29.20 & $31.30 \mathrm{ab}$ \\
INIAP-473 Boliche & $5.00 \mathrm{abc}$ & 30.00 & $31.70 \mathrm{ab}$ \\
Cuarentón & $5.30 \mathrm{abc}$ & 30.40 & $33.30 \mathrm{ab}$ \\
FTS Soberano & $5.00 \mathrm{abc}$ & 27.50 & $31.70 \mathrm{ab}$ \\
BRS Valente & $5.70 \mathrm{abc}$ & 28.80 & $31.70 \mathrm{ab}$ \\
\hline Promedio & $\mathbf{5 . 5 0}$ & $\mathbf{2 8 . 1 0}$ & $\mathbf{3 1 . 2 0}$ \\
\hline p-valor & $\mathbf{0 . 0 1}$ & $\mathbf{n s}$ & $\mathbf{0 . 0 1}$ \\
\hline CV (\%) & $\mathbf{1 7 . 6 3}$ & $\mathbf{1 4 . 8 7}$ & $\mathbf{8 . 3 3}$ \\
\hline
\end{tabular}

1, 2, ${ }^{3}$ Estadíos fenológicos reproductivos del cultivo de fréjol (Hall, 1994).

Medias seguidas por la misma letra no presentan diferencias estadísticas (Tukey, $\mathrm{p}>0.05$ ).

Soberano. Para el rendimiento, la variedad superior estadísticamente fue FTS Soberano en comparación con los demás materiales evaluados, seguido de las líneas promisorias Cf6 0-0-4-8, Cf6 0-0-4-9, Cf6 0-05-7 y EVG-16-08, y la variedad comercial INIAP473-Boliche. Sería recomendable evaluar el potencial productivo de estos seis materiales en más de una localidad y época de siembra, para confirmar si es el factor genotipo o ambiente, o inclusive si la población patogénica influencia en esta y las demás variables productivas.

Los valores máximos y mínimos obtenidos para las variables productivas estuvieron entre 3.0 a 30.0 para el número de vainas por planta, 9.4 a 174.7 para el número de granos por planta, 2.08 a 5.84 para el número de granos por vaina, $3.0 \mathrm{a} 36.8 \mathrm{~g}$ para el peso de granos por planta, 0.8 a 7.6 para vainas estériles y 76.7 a $1,130.5 \mathrm{~kg}$ $\mathrm{ha}^{-1}$ para el rendimiento.

Diferencias han sido obtenidas por otros autores en diversas investigaciones, para cada una de las variables productivas evaluadas en la presente investigación. Para el número de vainas por planta de 7.16 a 8.27 (Shimada et al., 2000), 26.67 a 38.38 (Infante et al., 2003), 7.56 a 16.40 (Santos et al., 2009) y 10.6 a 10.8 (Abrantes et al., 2011). Así también, para el número de granos por planta de 35.24 a 39.18 (Shimada et al., 2000) y 43.0 a 49.4 granos por planta (Abrantes et al., 2011). Igualmente, para el número de granos por vaina de 4.73 y 4.95 (Shimada et al., 2000), 3.7 a 5.1 (Leite et al., 2007), 2.0 a 5.1 (Morales-Rosales et al., 2008), 8.83 a 9.95 (Infante et al., 2003), 3.1 y 4.4 (Barrios-Gómez et al., 2010) y 3.9 a 4.6 semillas por vaina (Abrantes et al., 2011). Finalmente, para el rendimiento, valores de 858.2 a 1,459.8 (Folegatti et al., 1999); 1,747 (IAC-Carioca Pyatã) a 1,868 (IAC-Bico de Ouro) (Shimada et al., 2000), 2,124 (Meia Noite) a 2,189 (Novo Jalo) (Leite et al., 2007), en época de temporal (época lluviosa) de 1,117 y 3,615 (González-Torres et al., 2008), 393 (Rabo Peba) y 1,230 (Epace-10) (Santos et al., 2009), 1,771 (IAC Apuã) a 2,304 (Carioca Precoce) (Abrantes et al., 2011) y $1,556.25$ a $3,720.00 \mathrm{~kg} \mathrm{ha}^{-1}$ (Garcés-Fiallos, 2011a).

Las diferencias encontradas en este trabajo con los anteriormente mencionados, se debió principalmente al material genético utilizado y condiciones agroclimáticas. Se constató un rendimiento inferior en comparación con la mayoría de investigaciones referenciadas, posiblemente al establecimiento del experimento en época lluviosa, siendo este hecho comprobado por la cantidad total de precipitación pluvial total ocurrida (906.5 mm) (Cuadro 1). En el Ecuador esta condición es anormal para este cultivo según el INIAP (1999), quien menciona que para el establecimiento de fréjol arbustivo, voluble en asociación con maíz y voluble en monocultivo, se necesita precipitaciones entre 300 a 700,500 a 800 y 500 a $900 \mathrm{~mm}$, respectivamente. Esto es corroborado por Miyasaka et al. (1966), quienes en las localidades de Capão Bonito, Itapeva e Itararé, Brasil, demostraron que la producción de fréjol sufrió una fuerte caída, en consecuencia del exceso de agua en los meses de octubre y diciembre, y de la seca en noviembre, durante la mayor parte del período de floración-fructificación.

Para la severidad de las enfermedades foliares, se observó una nula relación entre el estadío fenológico R5 y los R6 y R7, así como entre estas variables sanitarias y todas las productivas (Cuadro 4). Ésto posiblemente ocurrió por el comportamiento diferenciado de cada material genético a cada enfermedad foliar en esta parte del Ecuador, puesto que un genotipo puede ser tolerante a una enfermedad y susceptible a otra, siendo este hecho corroborado por Garcés-Fiallos et al. (2012) y GarcésFiallos (2013). 
Cuadro 3. Componentes de rendimiento (número de vainas por planta, número de granos por planta, número de granos por vaina, peso de granos por planta y vainas estériles) y rendimiento ( $\left.\mathrm{kg} \mathrm{ha}^{-1}\right)$ de 16 materiales de fréjol evaluados durante la época lluviosa del 2011

\begin{tabular}{lcccccc}
\hline & \multicolumn{5}{c}{ Componentes de rendimiento } \\
\cline { 2 - 6 } Material genético & $\begin{array}{c}\text { Número de } \\
\text { vainas por } \\
\text { planta }\end{array}$ & $\begin{array}{c}\text { Número de } \\
\text { granos por } \\
\text { planta }\end{array}$ & $\begin{array}{c}\text { Número de } \\
\text { granos por } \\
\text { vaina }\end{array}$ & $\begin{array}{c}\text { Peso de granos } \\
\text { por planta } \\
\text { (g) }\end{array}$ & $\begin{array}{c}\text { Vainas } \\
\text { estériles }\end{array}$ & $\begin{array}{c}\text { Rendimiento } \\
\text { (kg ha-1 }^{-1}\end{array}$ \\
\hline Cf6 0-0-4-8 & $14.70 \mathrm{~b}^{1}$ & $52.00 \mathrm{~b}$ & $3.50 \mathrm{~b}$ & $18.50 \mathrm{~b}$ & $2.10 \mathrm{c}$ & $711.70 \mathrm{~b}$ \\
Cf6 0-0-4-9 & $13.70 \mathrm{~b}$ & $47.10 \mathrm{~b}$ & $3.43 \mathrm{~b}$ & $17.20 \mathrm{~b}$ & $3.20 \mathrm{c}$ & $535.90 \mathrm{~b}$ \\
Cf6 0-0-5-7 & $11.10 \mathrm{~b}$ & $37.50 \mathrm{~b}$ & $3.38 \mathrm{~b}$ & $13.20 \mathrm{c}$ & $4.20 \mathrm{~b}$ & $554.40 \mathrm{~b}$ \\
Cf4 0-0-2-1 & $8.00 \mathrm{~b}$ & $17.60 \mathrm{~b}$ & $2.15 \mathrm{~b}$ & $6.50 \mathrm{c}$ & $7.60 \mathrm{a}$ & $216.70 \mathrm{c}$ \\
Cf4 0-0-3-11 & $4.50 \mathrm{~b}$ & $9.40 \mathrm{~b}$ & $2.08 \mathrm{~b}$ & $3.40 \mathrm{c}$ & $6.80 \mathrm{a}$ & $96.70 \mathrm{c}$ \\
Cf4 0-0-4-8 & $12.40 \mathrm{~b}$ & $26.80 \mathrm{~b}$ & $2.17 \mathrm{~b}$ & $10.70 \mathrm{c}$ & $4.10 \mathrm{~b}$ & $332.50 \mathrm{c}$ \\
SER 03 & $4.10 \mathrm{~b}$ & $10.40 \mathrm{~b}$ & $2.42 \mathrm{~b}$ & $2.90 \mathrm{c}$ & $2.10 \mathrm{c}$ & $125.70 \mathrm{c}$ \\
SER 08 & $8.50 \mathrm{~b}$ & $32.80 \mathrm{~b}$ & $3.85 \mathrm{~b}$ & $9.10 \mathrm{c}$ & $1.60 \mathrm{c}$ & $280.90 \mathrm{c}$ \\
SER 31 & $3.00 \mathrm{~b}$ & $10.70 \mathrm{~b}$ & $3.58 \mathrm{~b}$ & $3.00 \mathrm{c}$ & $0.80 \mathrm{c}$ & $76.70 \mathrm{c}$ \\
CAL 96 & $9.70 \mathrm{~b}$ & $26.40 \mathrm{~b}$ & $2.73 \mathrm{~b}$ & $9.60 \mathrm{c}$ & $2.80 \mathrm{c}$ & $232.70 \mathrm{c}$ \\
EVG-16-08 & $26.10 \mathrm{a}$ & $147.50 \mathrm{a}$ & $5.64 \mathrm{a}$ & $23.20 \mathrm{~b}$ & $1.10 \mathrm{c}$ & $499.50 \mathrm{~b}$ \\
EVG-06-103 & $14.60 \mathrm{~b}$ & $44.60 \mathrm{~b}$ & $3.05 \mathrm{~b}$ & $16.10 \mathrm{~b}$ & $3.10 \mathrm{c}$ & $389.70 \mathrm{c}$ \\
INIAP-473-Boliche & $16.40 \mathrm{~b}$ & $52.80 \mathrm{~b}$ & $3.21 \mathrm{~b}$ & $17.90 \mathrm{~b}$ & $4.60 \mathrm{~b}$ & $592.50 \mathrm{~b}$ \\
Cuarentón & $9.60 \mathrm{~b}$ & $29.70 \mathrm{~b}$ & $3.11 \mathrm{~b}$ & $11.60 \mathrm{c}$ & $1.60 \mathrm{c}$ & $247.90 \mathrm{c}$ \\
FTS Soberano & $30.00 \mathrm{a}$ & $174.70 \mathrm{a}$ & $5.84 \mathrm{a}$ & $36.80 \mathrm{a}$ & $1.00 \mathrm{c}$ & $1130.50 \mathrm{a}$ \\
BRS Valente & $10.40 \mathrm{~b}$ & $58.10 \mathrm{~b}$ & $5.60 \mathrm{~b}$ & $8.80 \mathrm{c}$ & $1.70 \mathrm{c}$ & $314.70 \mathrm{c}$ \\
\hline Promedio & $\mathbf{1 2 . 3 0}$ & $\mathbf{4 8 . 6 3}$ & $\mathbf{3 . 4 8}$ & $\mathbf{1 3 . 0 3}$ & $\mathbf{3 . 0 3}$ & $\mathbf{3 9 6 . 1 7}$ \\
\hline $\boldsymbol{p}$-valor & $\mathbf{0 . 0 5}$ & $\mathbf{0 . 0 5}$ & $\mathbf{0 . 0 1}$ & $\mathbf{0 . 0 5}$ & $\mathbf{0 . 0 1}$ & $\mathbf{0 . 0 5}$ \\
\hline CV (\%) & $\mathbf{4 1 . 5 8}$ & $\mathbf{4 8 . 4 4}$ & $\mathbf{9 . 4 2}$ & $\mathbf{4 1 . 0 7}$ & $\mathbf{4 8 . 2 9}$ & $\mathbf{2 4 . 3 7}$ \\
\hline
\end{tabular}

${ }^{1}$ Medias seguidas por la misma letra no presentan diferencias estadísticas (Tukey, $\mathrm{p}>0.05$ ).

En el presente trabajo se cuantificaron en conjunto tres enfermedades foliares, mientras que la mustia hilachosa (principal enfermedad en esta parte del país) es la que mejor se relaciona con el rendimiento (GarcésFiallos, 2011a) y algunos de sus componentes (GarcésFiallos y Gamarra, 2012b), lo que probablemente podría haber influenciado este comportamiento. Contrariamente se encontró una relación significativa $(p<0.01)$ entre R6 y R7, mostrando un coeficiente de determinación de $0.83 \%$ (Cuadro 4).

En la relación simple realizada entre todos los caracteres productivos (Cuadro 4), fue evidenciada significancia estadística $(\mathrm{p}<0.01)$ entre la variable número de vainas por planta y las de número de granos por planta, peso de granos por planta y rendimiento de granos. Así también el número de granos por planta y las de número de granos por vaina, peso de granos por planta y rendimiento; y finalmente entre peso de granos por planta y de rendimiento.

El número de vainas por planta y granos por vaina son caracteres importantes, que pueden ser utilizados para el mejoramiento de fréjol con el objetivo de aumentar el rendimiento de granos (Barili et al., 2011). Pueden también ser encontrados coeficientes significativos de correlación fenotípica, genotípica y ambiental entre el rendimiento y las variables secundarias como número de vainas por planta y granos por vaina (Matos et al., 2009). El alto rendimiento de granos puede estar asociado con la producción de la biomasa aérea final, vainas normales $\mathrm{m}^{-2}$, granos normales $\mathrm{m}^{-2}$, granos vaina ${ }^{-1}$ y peso de 100 granos (Barrios-Gómez et al., 2010). La existencia de correlaciones significativas es un indicativo fuerte de viabilidad de selección indirecta para la obtención de ganancia en las variables denominadas secundarias (espesura del tallo, altura de inserción de la primera vaina en $\mathrm{cm}$, largura de la vaina, número de ramas con vainas, número de nudos, número de ramas y número de semillas por vaina) (Barili et al., 2010). Se encontraron como componentes secundarios importantes al número de vainas por planta, número de granos por planta y peso 
Cuadro 4. Coeficientes de relación simple de tres caracteres sanitarios (severidad de enfermedades durante los estadíos fenológicos R5, R6 y R7) y seis productivos (NVP: número de vainas por planta, NGP: número de granos por planta, NGV: número de granos por vaina, PGP: peso de granos por planta, VE: vainas estériles y R: rendimiento) en 16 materiales de fréjol evaluados durante la época lluviosa del 2011

\begin{tabular}{|c|c|c|c|c|c|c|c|c|c|}
\hline \multirow{2}{*}{$\begin{array}{l}\text { Caracteres } \\
\text { agronómicos }\end{array}$} & \multicolumn{3}{|c|}{ Severidad de enfermedades } & \multicolumn{6}{|c|}{ Producción de granos } \\
\hline & R5 & R6 & R7 & NVP & NGP & NGV & PGP & $\mathbf{V E}$ & $\mathbf{R}$ \\
\hline R5 & 1.00 & $0.23 \mathrm{~ns}$ & $0.11 \mathrm{~ns}$ & $0.07 \mathrm{~ns}$ & $0.02 \mathrm{~ns}$ & $0.01 \mathrm{~ns}$ & $0.08 \mathrm{~ns}$ & $0.00 \mathrm{~ns}$ & $0.13 \mathrm{~ns}$ \\
\hline R6 & & 1.00 & $0.83 * *$ & $0.07 \mathrm{~ns}$ & $0.05 \mathrm{~ns}$ & $0.01 \mathrm{~ns}$ & $0.03 \mathrm{~ns}$ & $0.15 \mathrm{~ns}$ & $0.09 \mathrm{~ns}$ \\
\hline $\mathrm{R} 7$ & & & 1.00 & $0.06 \mathrm{~ns}$ & $0.03 \mathrm{~ns}$ & $0.02 \mathrm{~ns}$ & $0.01 \mathrm{~ns}$ & $0.27 \mathrm{~ns}$ & $0.05 \mathrm{~ns}$ \\
\hline NVP & & & & 1.00 & $0.91 * *$ & $0.46 \mathrm{~ns}$ & $0.93^{* *}$ & $0.10 \mathrm{~ns}$ & $0.75^{* *}$ \\
\hline NGP & & & & & 1.00 & $0.69 * *$ & $0.82 * *$ & $0.18 \mathrm{~ns}$ & $0.64^{* *}$ \\
\hline NGV & & & & & & 1.00 & $0.42 \mathrm{~ns}$ & $0.43 \mathrm{~ns}$ & $0.33 \mathrm{~ns}$ \\
\hline PGP & & & & & & & 1.00 & $0.11 \mathrm{~ns}$ & $0.89 * *$ \\
\hline VE & & & & & & & & 1.00 & $0.10 \mathrm{~ns}$ \\
\hline $\mathrm{R}$ & & & & & & & & & 1.00 \\
\hline
\end{tabular}

** Significativo al 1\% de probabilidad por la prueba de $\mathrm{F}$. ns No significativo al $1 \%$ de probabilidad por la prueba de F.

de granos por planta, por haber obtenido regresiones significativas $(\mathrm{p}>0.01)$ con el rendimiento.

En función del análisis de conglomerados, utilizando el método de Ward, se obtuvo una distancia euclidiana promedio de 7.00 y una correlación cofenética de 0.668 (Figura 1). Este mismo análisis separó el germoplasma en tres grupos, en función de todos sus componentes de rendimiento (no fue contabilizado para este análisis el número de vainas estériles), mostrándose el tercer grupo con características productivas superiores (FTS Soberano y EVG-16-08).

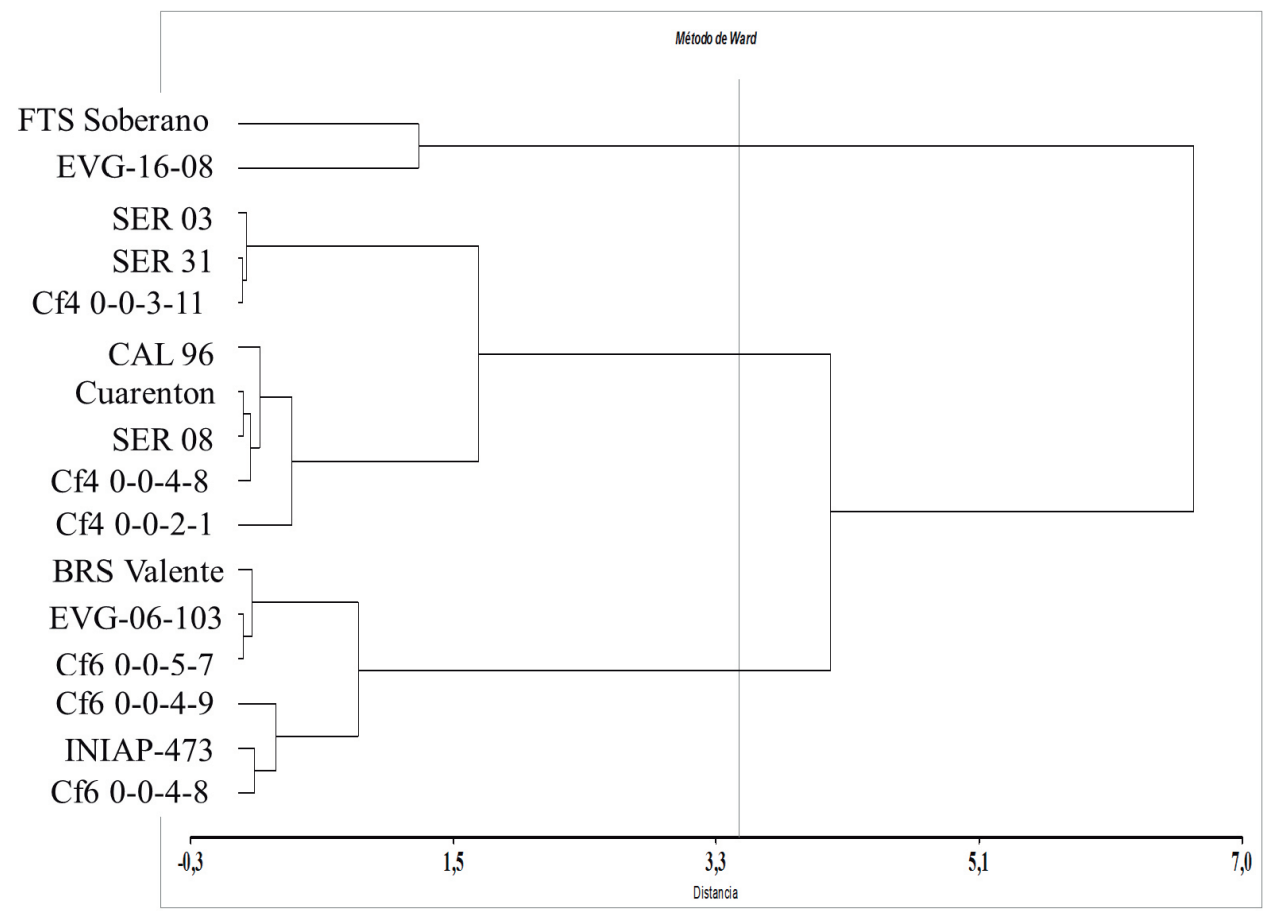

Figura 1. Dendograma de similaridad basado en todos los componentes productivos excepto vainas estériles, obtenidos en los 16 materiales de fréjol evaluados durante la época lluviosa del 2011 


\section{Conclusiones}

$\mathrm{L}$ as líneas Cf4 0-0-2-1 y EVG-16-08 presentaron la menor severidad final (estadío fenológico R7) de enfermedades. Se determinaron como componentes importantes al número de vainas por planta, número de granos por planta y peso de granos por planta, por haber obtenido regresiones significativas $(p<0.01)$ con el rendimiento. En función del análisis de conglomerados, se destacaron la variedad extranjera FTS Soberano y la línea promisoria avanzada EVG-16-08 con cualidades productivas superiores.

\section{LITERATURA CITADA}

Abrantes, F.L., M. de Sá, L.C. Domingues de Souza, P. Pina da Silva, H.M. Simidu, M. Andreotti, S. Buzetti, W.V. Velério-Filho, e N. Arruda. 2011. Uso de regulador de crescimento em cultivares de feijão de inverno. Pesquisa Agropecuária Tropical 41(2): 148-154.

Amorim, E.P., N.P. Ramos, M.R.G. Ungaro, e T.A.M. Kiihl. 2008. Correlações e análise de trilha em girassol. Bragantia 67(2): 307-316.

Barili, L.D., M.N. do Vale, F. da Rocha, D.S. Rozetto, M. Coan, J.L. Coimbra, C.M. Coelho, C. de Souza. 2010. Componentes do rendimento em acessos de feijão. Revista de Ciências Agroveterinárias 9(2): 125-133.

Barili, L.D., M.N. do Vale, P.P. Morais, J.N. Baldissera, C. de Almeida, F. da. Rocha, G, Valentini, J. Bertoldo, J.L. Coimbra, e A.F. Guidolin. 2011. Correlação fenotípica entre componentes do rendimento de grãos de feijão comum (Phaseolus vulgaris L.). Semina: Ciências Agrárias 32(4): 1263-1274.

Barrios-Gómez, E.J., C. López-Castañeda, J. KohashiShibata, J. Acosta-Gallegos, S. Miranda-Colín, N. Mayek-Pérez. 2010. Rendimiento de semilla, y sus componentes en frijol flor de mayo en el centro de México. Agrociencia 44(4): 481-489.

Bassanezi, R.B., L. Amorim, A. Bergamin-Filho, and B. Hau. 1998. Effects of bean line pattern mosaic virus on the monocyclic components of rust and angular leaf spot of Phaseolus bean at different temperatures. Plant Pathology 47(3): 289-298.

Bianchini, A., A.C. Maringoni, e S.M.T.P.G. Carneiro. 2005. Doenças do feijoeiro (Phaseolus vulgaris). Em: Kimati, H., L. Amorim, J.A.M. Rezende, A. Bergamin Filho e L.E.A. Camargo [Eds.]. Manual de Fitopatologia. Vol. 2. 4a ed. Agronômica Ceres, São Paulo. pp. 333-349.

Coelho, A.D.F., A.A. Cardoso, C.D. Cruz, G.A.A. Araújo, M.R. Furtado, e C.L.F. Amaral. 2002.
Herdabilidades e correlações da produção do feijão e dos seus componentes primários, nas épocas de cultivo da primavera-verão e do verão-outono. Ciência Rural 32(2): 211-216.

Ernest, E.G., E. Falconí-Castillo, E. Peralta-Idrovo, J. Kelly. 2008. Encuesta a productores para orientar el fitomejoramiento en frijol en Ecuador. Agronomía Mesoamericana 19(1): 07-18.

Espinoza, A. 2004. Combate de enfermedades. En: R. Guamán, C. Andrade, y J. Álava. Guía para el cultivo del fréjol en el Litoral Ecuatoriano. Boletín Divulgativo No 316. Instituto Nacional de Investigaciones Agropecuarias-INIAP, Boliche. p. 21-28.

Folegatti, M., V.P. Paz, e A. de Oliveira. 1999. Rendimento do feijoeiro irrigado submetido a diferentes lâminas de água com irrigação por sulco. Revista Brasileira de Engenharia Agrícola e Ambiental 3(3): 281-285.

Garcés-Fiallos, F.R. 2010. Doenças causadas por vírus na cultura de feijoeiro. Ciencia y Tecnología 3(2): 1-6.

Garcés-Fiallos, F.R. 2011a. Modelo de ponto crítico para estimar danos causados pela mela na cultura do feijoeiro. Ciencia y Tecnología 4(1): 1-4.

Garcés-Fiallos, F.R. 2011b. Ocurrencia e intensidad de enfermedades foliares y radiculares de fréjol en el Trópico húmedo ecuatoriano. In: VIII Simposio Internacional de Recursos Genéticos para América Latina y el Caribe, 2011, Quito. Quito: INIAP, Publicación Miscelánea. 3 p.

Garcés-Fiallos, F.G., e Y.H.V. Gamarra. 2012a. Intensidade de doenças foliares e radiculares e componentes de rendimento de sete genótipos de feijão em Quevedo, Equador. Tropical Plant Pathology 37(Suplemento): 449 (Resumen).

Garcés-Fiallos, F.G., e Y.H.V, Gamarra. 2012b. Relação entre mela e componentes de rendimento de sete genótipos de feijão em Quevedo, Equador. Tropical Plant Pathology 37(Suplemento): 450 (Resumen).

Garcés-Fiallos, F.R., R.G. Zabala-Palacios, T.G. DíazCoronel, D.F. Vera-Avilés. 2012. Evaluación agronómica y fitosanitaria de germoplasma de fréjol en el trópico húmedo ecuatoriano. Revista Científica UDO Agrícola 12(2): 230-240.

Garcés-Fiallos, F. R. 2013. Cuantificación de enfermedades en líneas promisorias y variedades de fréjol en Quevedo, Ecuador. Biotecnología en el Sector Agropecuario y Agroindustrial 11(1): 196 -207.

Godoy-Montiel, L., G. Díaz, G. Vásconez-Montúfar, E. Defaz, B. González. 2011. Evaluación de dos variedades de fréjol durante tres épocas de siembra bajo sistema de cultivo asociado con maíz. Ciencia y Tecnología 4(1): 5-11. 
González-Torres, G., F.M. Mendoza-Hernández, J. Covarrubias-Prieto, N. Morán-Vázquez, J.A. Acosta-Gallegos. 2008. Rendimiento y calidad de semilla de frijol en dos épocas de siembra en la región del Bajío. Agricultura Técnica en México 34(4): 421-430.

Guamán, J.R., V.C. Andrade, A.J. Álava. 2003. INIAP473-BOLICHE e INIAP 474-DORALISA. Variedades mejoradas de fréjol arbustivo para el Litoral Ecuatoriano. Boletín divulgativo No 297. INIAP, Boliche. 2003. 20 pp.

Hall, R. 1994. Compendium of bean diseases. 2nd edition. APS Press, Minnesota. 73 pp.

Instituto Nacional de Estadística y Censos. 2002. III Censo Nacional Agropecuario. Resultados Nacionales y Provinciales. INEC, Ministerio de Agricultura y Ganadería-MAG, Servicio de Servicio y Censo Agropecuario-SICA. Quito, Ecuador. 255 pp.

Instituto Nacional Autónomo de Investigaciones Agropecuarias. 1999. Guía de Cultivos. INIAP, Quito. 186 pp.

Infante, N., P. Madriz, T. González. 2003. Fases de desarrollo y componentes del rendimiento de tres cultivares de fríjol mungo (Vigna radiata (L) Wilczek) en Maracay, estado Aragua, Venezuela. Revista Facultad de Agronomía (LUZ) 20(40): 417-429.

INFOSTAT. InfoStat versión 2011. Grupo InfoStat, FCA, Universidad Nacional de Córdoba, Argentina. 2011.

Kuruvadi, S. y H.M. Cortinas-Escobar. 1987. Papel de componentes de rendimiento, correlaciones y sus implicaciones en el mejoramiento genético del frijol (Phaseolus vulgaris, L.). Agraria 3(1): 1-15.

Leite, U., G.A. Araújo, G. Miranda, R. Vieira, J.E. Carneiro, A. Pires. 2007. Rendimento de grãos e componentes de rendimento do feijoeiro em função da aplicação foliar de doses crescentes de molibdênio. Acta Scientiarum Agronomy 2(1):113120.

Matos, C.H.A., R.L. Ferreira-Gomes, M. Moura-Rocha, F.R. Freire-Filho, e A.C. de Almeida-Lopes. 2009. Potencial produtivo de progênies de feijão-caupi com arquitetura ereta de planta. Ciência Rural 39(2): 348-354.

Miyasaka, S., H.A.A. Mascarenhas e M. Alcover. 1966. Adubação mineral do feijoeiro VII - Efeitos de $\mathrm{N}, \mathrm{P}, \mathrm{K}, \mathrm{S}$, da calagem e de uma mistura de micronutrientes, no sul do planalto paulista. Bragantia 25(35): 385-392.

Morales-Rosales, E.J., J.A.S. Escalante-Estrada y J.A. López-Sandoval. 2008. Crecimiento, índice de cosecha y rendimiento de frijol (Phaseolus vulgaris L.) en unicultivo y asociado con girasol (Helianthus annuus L.). Universidad y Ciencia 24(1): 1-10.

Nechet, K.L. e B.A. Halfeld-Vieira. 2007. Reação de cultivares de feijão-caupi à mela (Rhizoctonia solani) em Roraima. Fitopatologia Brasileira 32: 424-428.

Rodríguez, E., E. Lorenzo, M. Acosta, F. González, B. Mora y G. Godoy. 1999. Manejo de la mustia hilachosa (Thanatephorus cucumeris (Frank)) en el cultivo del frijol común (Phaseolus vulgaris L.). Agronomía Mesoamericana 10(1): 99-108.

Santos, J.F., J.I. Tavares-Grangeiro, C.H. de Brito, e M. do C.C. Almeida-Santos. 2009. Produção e componentes produtivos de variedades de feijão caupi na microregião Cariri Paraibano. Engenharia Ambiental 6(1): 214-222.

SAS/STAT ${ }^{\circledR}$ Versão 9.0 do sistema SAS para Windows. Copyright 2002 SAS Institute Inc. Cary. NC. USA.

Shimada, M.M., O. Arf e M.E. De Sá. 2000. Componentes do rendimento e desenvolvimento do feijoeiro de porte ereto sob diferentes densidades populacionais. Bragantia 59(2): 181-187.

Silva, F. de A.S. e C.A.V. de Azevedo. 2002. Versão do programa computacional Assistat para sistema operacional Windows. Revista Brasileira de Produtos Agroindustriais 4(1): 71-78.

Voysest, V.O. 2000. Mejoramiento genético del frijol (Phaseolus vulgaris L.). Legado de variedades de América Latina 1930 - 1999. Centro Internacional de Agricultura Tropical-CIAT, Cali. 195 pp.

Zaiter, H.Z., D.P. Coyne and J.R. Steadman. 1990. Coinoculation effects of the pathogens causing common bacterial blight, rust, and bean common mosaic in Phaseolus vulgaris. Journal of the American Society for Horticultural Science 115(2): 319-323. 